\title{
Factors Regulating the Effects of Hippocampal Inactivation on Renewal of Conditional Fear After Extinction
}

\author{
Kevin A. Corcoran ${ }^{1}$ and Stephen Maren ${ }^{1,2,3}$ \\ ${ }^{1}$ Department of Psychology and ${ }^{2}$ Neuroscience Program, University of Michigan, Ann Arbor, Michigan 48109, USA
}

\begin{abstract}
After extinction of fear to a Pavlovian conditional stimulus (CS), contextual stimuli come to regulate the expression of fear to that CS. There is growing evidence that the context dependence of memory retrieval after extinction involves the hippocampus. In the present experiment, we examine whether hippocampal involvement in memory retrieval after extinction is related to the history of CS presentations in the context used for retrieval testing. We used infusions of muscimol to inactivate the dorsal hippocampus $(\mathrm{DH})$ during postextinction retrieval tests that were conducted in contexts that differed in their history of CS presentations in that context. We found that DH inactivation affected the context-dependent retrieval of extinction (i.e., renewal) when testing occurred in a context that had no history of CS exposure, but not in a context that reliably predicted the CS. These results are discussed in terms of theories regarding the role of the hippocampus in contextual memory retrieval.
\end{abstract}

Extinction learning, in which the amplitude and probability of Pavlovian conditional responses (CRs) decrease as a result of nonreinforced conditional stimulus (CS) presentations (Pavlov 1927), provides a model behavioral paradigm for the clinical treatment of fear disorders (Davis and Myers 2002). Rather than abolish the conditioning memory, however, extinction learning involves new learning of an inhibitory memory that can interfere with expression of the conditioning memory (Bouton 1994, 2002). One interesting aspect of extinction is that, unlike the retrieval of CS-unconditional stimulus (US) associations learned during conditioning, the retrieval of CS-'no US' memories learned during extinction is highly dependent upon the context in which retrieval occurs; outside the extinction context, renewal of behavior occurs (Bouton and Bolles 1979). Whereas the term renewal is used to describe the return of conditioned responding outside the extinction context, available evidence suggests that it is less a result of the promotion of the conditioning memory as it is the suppression of the extinction memory (Davis and Myers 2002). Several theories have been set forth to explain how behavior comes under contextual control, including contextual indexing of multiple stimulus memories (Hirsh 1974), direct context-US associations (Lovibond et al. 1984; c.f. Bouton and Swartzentruber 1986), Pavlovian occasion-setting (Bouton and Swartzentruber, 1986), and incidental context-CS associations (Good et al. 1998). Whereas the neurobiology mediating contextual learning and memory in general, and extinction learning and retrieval in particular, has received considerable attention, the systems underlying the context dependency of extinction retrieval are not as well studied.

The hippocampus has an important role in both contextual learning (Kim and Fanselow 1992; Maren et al. 1997; Frankland et al. 1998; Good et al. 1998; Rudy and O'Reilly 2001) and contextual retrieval (Good and Honey 1991; Honey and Good 1993; Holt and Maren 1999). It has thus been the focus of research into the brain systems supporting the contextual retrieval of fear extinction (Wilson et al. 1995; Frohardt et al. 2000; Corcoran and

\section{${ }^{3}$ Corresponding author.}

E-MAIL maren@umich.edu; FAX (734) 763-7480.

Article and publication are at http://www.learnmem.org/cgi/doi/10.1101/ Im.78704.
Maren 2001), although these investigations have yielded mixed results. Early studies found no effect of pretraining radiofrequency lesions of the fimbria/fornix (Wilson et al. 1995) or neurotoxic hippocampal lesions (Frohardt et al. 2000) on the context specificity of fear extinction assessed using bar-press suppression. However, we recently demonstrated an effect of dorsal hippocampal (DH) inactivation on renewal of conditional freezing to an extinguished CS (Corcoran and Maren 2001). This recent effect parallels earlier results on the effect of $\mathrm{DH}$ inactivation on the context-specific expression of latent inhibition (Holt and Maren 1999; Maren and Holt 2000).

There are several differences between these studies that might account for their discrepant results (Table 1). First, lesions and reversible inactivation may yield different behavioral outcomes, as other neural systems may compensate for irreversible brain damage (Maren et al. 1997). Second, the behavioral measures of fear (suppression vs. freezing) may be differentially sensitive to hippocampal damage, although this seems unlikely insofar as hippocampal lesions do affect the shock-elicited reinstatement of bar-press suppression (Wilson et al. 1995; Frohardt et al. 2000). Third, the nature of the retrieval test might engender different levels of ambiguity, which affects the degree of hippocampal involvement (e.g., Shapiro and Olton 1994; McNaughton and Wickens 2003). In the work by Bouton and colleagues, all retrieval testing was conducted in the same context as that used for initial fear conditioning (context A), and renewal was demonstrated by greater levels of suppression among rats extinguished in a second context (context B; ABA > AAA). In our previous work, all retrieval testing was conducted outside of the conditioning context, in contexts that had either hosted extinction training (B) or had no history of CS exposure (context C). In this case, renewal was demonstrated by greater performance of rats tested in the neutral context compared with rats tested inside their extinction context $(\mathrm{ABC}>\mathrm{ABB})$. The renewal contexts in these studies therefore differed in their histories with respect to the CS, insofar as the CS had always been followed by shock in context $\mathrm{A}$, but had never been presented in context C. Lastly, it may simply be the case that involving three contexts in $\mathrm{ABC}$ renewal, as opposed to the two contexts in ABA renewal, somehow makes it more reliant on the hippocampus. 
Table 1. Experimental Designs

\begin{tabular}{|c|c|c|c|c|c|}
\hline \multirow[b]{2}{*}{ Experiment } & \multicolumn{3}{|c|}{ Phase } & \multirow[b]{2}{*}{ Treatment } & \multirow[b]{2}{*}{ Context-CS History } \\
\hline & Conditioning & Extinction & Test & & \\
\hline \multirow{4}{*}{$\begin{array}{l}\text { Frohardt et. al. 2000; } \\
\text { Wilson et. al. 1995 } \\
\text { Corcoran \& Maren } 2001\end{array}$} & ${ }^{\mathrm{a}} \mathrm{AT}+$ & AT - & AT - & AAA & Mixed \\
\hline & ${ }^{\mathrm{a}} \mathrm{AT}+$ & BT - & AT - & ABA & Conditioning \\
\hline & AT+ & BT - & ${ }^{\mathrm{b}} \mathrm{BT}-$ & $A B B$ & Extinction \\
\hline & $\mathrm{AT}+$ & BT - & ${ }^{\mathrm{b}} \mathrm{CT}-$ & $A B C$ & None \\
\hline \multirow[t]{4}{*}{ This study } & AT+ & AT - & ${ }^{\mathrm{b}} \mathrm{AT}-$ & AAA & Mixed \\
\hline & $\mathrm{AT}+$ & AT - & ${ }^{\mathrm{b}} \mathrm{BT}-$ & $\mathrm{AAB}$ & None \\
\hline & AT+ & BT - & ${ }^{\mathrm{b}} \mathrm{AT}-$ & ABA & Conditioning \\
\hline & AT+ & $\mathrm{BT}-$ & ${ }^{\mathrm{b}} \mathrm{BT}-$ & $A B B$ & Extinction \\
\hline
\end{tabular}

$\mathrm{A}, \mathrm{B}, \mathrm{C}=$ experimental contexts; $\mathrm{T}=$ tone $\mathrm{CS} ;+=\mathrm{US} ;-=$ no US. ${ }^{a}$ permanent lesions made prior to training.

binfusions performed prior to testing.

gesting that mere placement of the guide cannulas in the $\mathrm{DH}$ had no significant effect on behavior.

\section{Behavior}

Freezing averaged across the first five CS-alone presentations of each extinction day is shown in Figure 3. We used the data from the first five extinction trials because they serve as a reliable measure of tone freezing that is not confounded by within-session extinction. Freezing to the tone CS declined significantly across the five extinction days $\left[F_{(3,126)}=102.5 ; P<0.0001\right]$. There were no significant interactions of extinction day $\times$ test day infusion $\left[F_{(3,126)}=0.91\right]$, extinction

In this study, we tested these possibilities by using pharmacological inactivation of the DH prior to testing in two-context renewal designs that differed in the history of CS exposure in the context used for retrieval testing. Testing was conducted either in the conditioning context (ABA), the extinction context (ABB), a neutral context in which neither conditioning nor extinction had occurred (AAB), or in a context in which both conditioning and extinction had occurred (AAA; see Table 1). In keeping with previous results, we expected normal retrieval of extinction in $\mathrm{AAA}$ and $\mathrm{ABB}$ rats after hippocampal inactivation. In contrast, we expected that DH inactivation would disrupt the context dependency of extinction when the retrieval test was conducted in a context with no previous history of CS exposure (AAB). Our results confirm this outcome, suggesting that the hippocampus is important for extinction renewal when the test context provides ambiguous information about the associative history of a Pavlovian CS.

\section{RESULTS}

\section{Histology}

The photomicrograph in Figure 1 illustrates a representative cannula placement in the DH. Figure 2 represents the injection cannula tip placements for all rats included in the analysis. Cannula placements were symmetrical throughout the rostral-caudal extent of the DH, and did not consistently differ across groups.

Placement of the guide cannulas into the DH damaged some cortical tissue and caused compression of hippocampal tissue. This damage was limited to the area immediately surrounding the cannulas. The pattern of results from saline controls in this experiment (see below) did not differ from that of unoperated animals described previously (Corcoran and Maren 2001), sug-

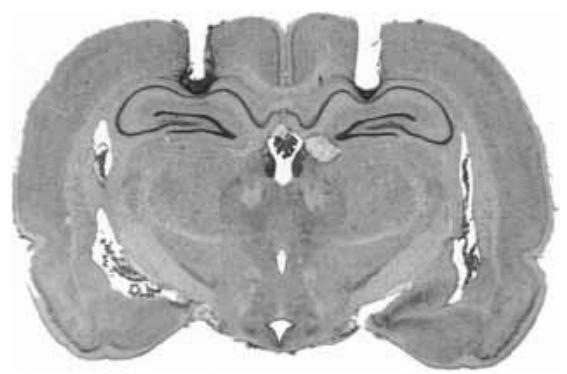

Figure 1 Cannula placement in the dorsal hippocampus. Photomicrograph showing a thionin-stained coronal section from the brain of a rat with representative cannula placements in the dorsal hippocampus. day $\times$ test context (Consistent/Inconsistent [CON/INCON]) $\left[F_{(3,126)}=1.28\right]$, or extinction day $\times$ test day infusion $\times$ test context $\left[F_{(3,126)}=0.86\right]$ on acquisition of extinction, indicating that the decrease in freezing across extinction days was equivalent for animals in all groups.

Retrieval testing occurred either inside rats' extinction context (CON: AAA, ABB) or in another context (INCON: ABA, AAB). Conditional freezing during the first minute of the 8-min CS (freezing during the first minute after tone onset was normalized by subtracting rats' pre-tone freezing) is shown in Figure 4. Data were analyzed separately using 2-way ANOVAs for the different renewal procedures (AAA/AAB vs. $\mathrm{ABB} / \mathrm{ABA})$.

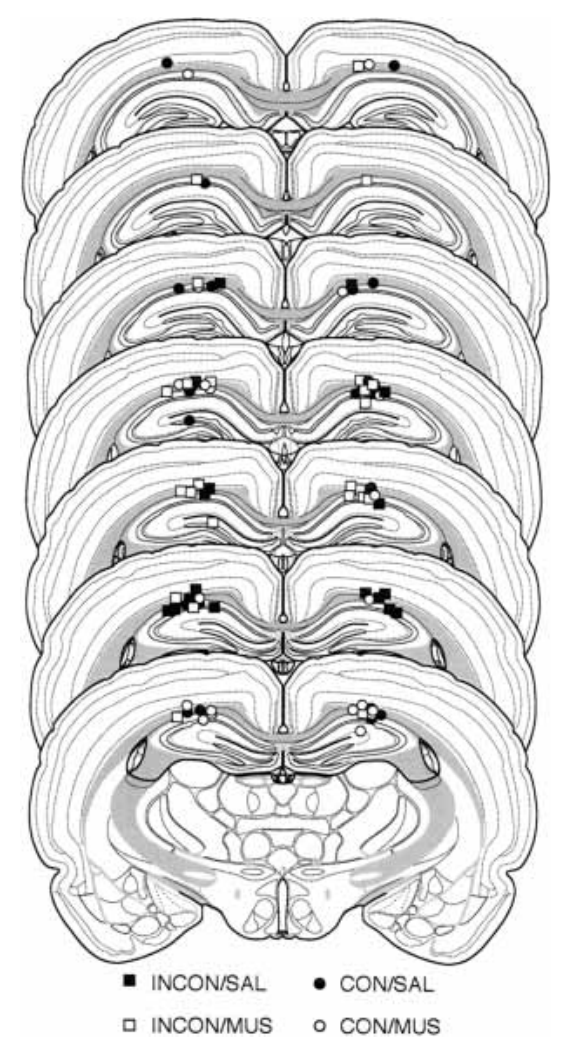

Figure 2 Illustration of injection cannula placements in the dorsal hippocampus. Placements represented are from all rats included in the final analysis (CON/SAL, •; CON/MUS, O; INCON/SAL, в; INCON/MUS, 口). Atlas templates adapted from Swanson (1992). 


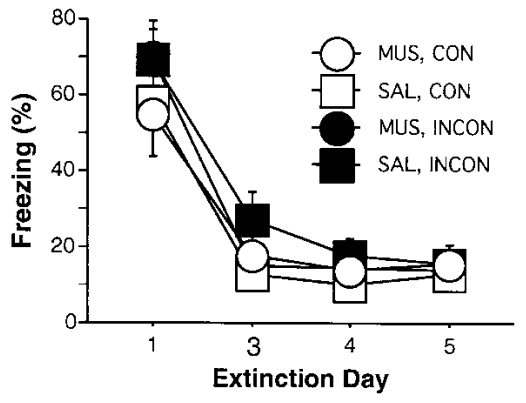

Figure 3 Extinction to the tone CS. Mean ( \pm SEM) percentage of freezing for the first five CS presentations across the $5 \mathrm{~d}$ of extinction in contexts $\mathrm{A}$ and $\mathrm{B}$. The group labels refer to the treatment conditions that would later be imposed during retrieval testing (not during extinction training). Data were not collected on day two of extinction due to a technical problem.

In the $\mathrm{AAA} / \mathrm{AAB}$ condition, there were no main effects of test context or infusion $\left[F \mathrm{~s}_{(1,20)}=1.42\right.$ and 1.73 , respectively], although there was a significant interaction of test context $\times$ infusion $\left[F_{(1,20)}=4.7 ; P<0.05\right]$. Post hoc tests $(P<0.05)$ indicated that rats in the CON/SAL condition froze less than INCON/ SAL rats, whereas there was no difference between CON/MUS and INCON/MUS rats. Moreover, low freezing levels among rats that had received muscimol infusions were no different from those among rats in the CON/SAL condition. In the ABB/ABA condition, there was a main effect of test context $\left[F_{(1,19)}=17.3\right.$; $P<0.001]$, but no effect of infusion and no interaction of test context $\times$ infusion $\left[F \mathrm{~s}_{(1,19)}=0.92\right.$ and 0.47 , respectively]. Post hoc tests $(P<0.05)$ revealed that rats tested in their extinction context $(\mathrm{CON})$ froze less than rats tested outside of their extinction context (INCON), whereas there was no difference between MUS and SAL rats tested in their extinction context and no difference between MUS and SAL rats tested outside of their extinction context.

Therefore, although renewal was present in both test procedures, it was only disrupted by hippocampal inactivation when the inconsistent context had no history of CS exposure (AAB). Renewal was intact after muscimol infusions when testing occurred in the conditioning context (ABA). It should be noted that the degrees of renewal in $\mathrm{AAB} / \mathrm{SAL}$ and $\mathrm{ABA} / \mathrm{SAL}$ rats were quite similar, so it is unlikely that the differential effect of muscimol in those groups was due to the different renewal designs fostering different levels of freezing.

\section{DISCUSSION}

The present experiments were designed to further our understanding of the role of the dorsal hippocampus in the contextual retrieval of fear memories after extinction. Earlier studies have led to disparate conclusions as to the role of the DH in renewal of conditional fear, although direct comparison of these conclusions have been hampered by the fact that they resulted from testing different hippocampal manipulations in different renewal paradigms. Earlier studies (Wilson et al. 1995; Frohardt et al. 2000) found no role for the hippocampus in renewal after making permanent lesions in an ABA renewal design, whereas our previous data (Corcoran and Maren 2001) suggested a role for the hippocampus after temporary hippocampal inactivation in an $A B C$ renewal design. The results of the present study support our earlier findings for a role of the $\mathrm{DH}$ in renewal by demonstrating that inactivation prior to testing disrupts the contextual retrieval of extinction memory in an $\mathrm{AAB}$ renewal design, which has many similarities to the $\mathrm{ABC}$ design in our earlier work (no history of CS exposure in test context). However, in contrast to the $\mathrm{AAB}$ design, we found that renewal in an $\mathrm{ABA}$ design was unaffected by hippocampal inactivation. This is consistent with the failure of pretraining fornix or hippocampal lesions to affect renewal in the ABA design (Wilson et al. 1995; Frohardt et al. 2000). It is important to note that the effects of hippocampal inactivation on fear renewal are not due to impairments in CS-US memory retrieval or the ability to perform the freezing response, a deficit in context processing (Holt and Maren 1999), or a statedependent context shift (as this would predict high levels of freezing among all rats receiving muscimol prior to test).

These results add to a growing body of knowledge about the role of the hippocampus in mediating the contextual retrieval of memories in Pavlovian conditioning paradigms (Holt and Maren 1999; Corcoran and Maren 2001). One important issue that remains, however, is why the hippocampus plays a role in $\mathrm{AAB}$ and $\mathrm{ABC}$, but not $\mathrm{ABA}$, renewal. One possibility is that ambiguity in the relationship between the test context and the CS engages the hippocampus to drive renewal. In both $\mathrm{ABA}$ and $\mathrm{ABB}$ groups, the testing context has been associated with either training or extinction to the CS, but not both. Therefore, the testing context has an unambiguous relationship with the CS. In AAA, AAB, and $\mathrm{ABC}$ groups, the testing context has been associated with both training and extinction (AAA) or neither process (AAB, $\mathrm{ABC}$ ). In these situations, the testing context may yield more interference between retrieval of CS-US and CS-no US memories; hippocampal involvement in renewal may therefore be a consequence of the need for reduction in ambiguity between these competing memories. It is important, then, to explain the nature of the effects seen in these ambiguous situations, that is, why is extinction behavior, rather than renewal, demonstrated among AAA, $\mathrm{AAB}$, and $\mathrm{ABC}$ rats after muscimol infusions?

One simple explanation is that during testing in an ambiguous context, rats normally respond according to the first thing learned about the CS (in this case, that the CS predicts shock) and renewal is observed. Perhaps, after hippocampal inactivation, rats respond according to the most recent thing learned about the CS - that the CS is not reinforced-and extinction behavior is observed. This pattern of effects could therefore be described such that when an ambiguous CS is tested in an ambiguous context, normal rats display a primacy effect, whereas rats with inactivated hippocampi display a recency effect. There are two arguments that can be made against this case, however. First, we suggest that the AAA condition presents rats with an ambiguous $\mathrm{CS}$ in an ambiguous context. In this situation, rats with intact hippocampi still retrieve CS-no US memories and demonstrate

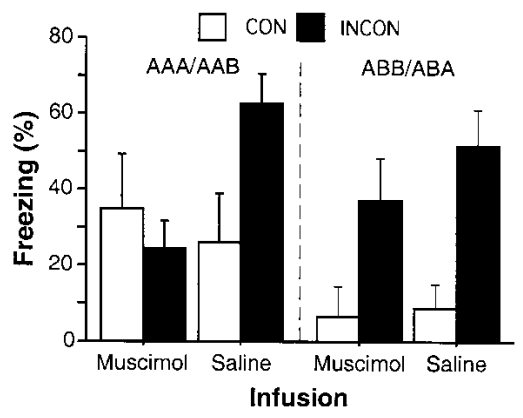

Figure 4 Hippocampal inactivation disrupts renewal of fear in contexts that are uninformative as to the meaning of the CS. Mean ( \pm SEM) percentage of freezing during the first minute after CS onset during testing. Rats were tested either in the same context in which extinction took place (CON, open bars) or in the context in which no CS-alone presentations were given during the extinction phase of training (INCON, filled bars). Data are separated by whether rats were tested in a context with an ambiguous history of CS presentations (AAA/AAB renewal; left) or in an unambiguous context ( $\mathrm{BBA} / \mathrm{ABB}$ renewal; right). 
low levels of freezing, rather than the high freezing levels that a primacy effect would otherwise predict. Moreover, when an ambiguous CS is tested in an ambiguous context in a latent inhibition experiment (Holt and Maren 1999), in which CS-no US presentations occur prior to CS-US presentations, rats normally respond according to the most recent thing learned about the CS; that is, they demonstrate high levels of freezing. After hippocampal inactivation, rats respond according to the first meaning of the CS and demonstrate low levels of freezing. In latent inhibition, therefore, hippocampal inactivation results in a shift from recency to primacy. Because context specificity in both latent inhibition and extinction seems to be mediated by the same neural systems, it is unlikely that engaging or disrupting this system would lead to opposite patterns of effects between the two behaviors.

It is well-known that memory retrieval is facilitated to the extent that the contextual cues present at the time of memory retrieval are similar to those present at the time of memory encoding (Spear 1973; Tulving and Thomson 1973). According to Hirsh (1974), the hippocampus is involved in using contexts to facilitate memory retrieval when stimuli acquire multiple meanings across contexts (such as CS-US in context A and CS-no US in context B); the hippocampus stores these multiple stimulus meanings according to a contextual index, and later uses this index for the contextual retrieval of the proper stimulus meaning. In the absence of a functional hippocampus, responding to the stimulus reverts to performance line responding, which is driven by the summated present and prior meanings of the stimulus (Hirsh 1974; Maren and Holt 2000). After hippocampal inactivation in $\mathrm{AAB}$ renewal, for example, $150 \mathrm{CS}$-no US presentations outweighed the five CS-US presentations, and extinction memory was expressed outside of the extinction context. Hirsh's theory, however, suggests that ABA renewal should be affected by hippocampal manipulations, although converging evidence (present results; Wilson et al. 1995; Frohardt et al. 2000) has demonstrated otherwise. It is therefore important to determine which feature(s) of the testing context engage the hippocampus for proper contextual memory retrieval.

It has been suggested that the amount of interference present at the time of testing is the critical variable in determining whether the hippocampus is implicated in a particular task (McNaughton and Wickens 2003). The hippocampus has long been considered a structure important for reducing susceptibility to interference during memory retrieval (Winocur 1979, 1985). In hippocampal-dependent tasks, increasing interference amplifies the deficits caused by hippocampal lesions (Wan et al. 1994). Interference occurs when two or more conflicting memories are similarly and highly primed; this conflict is detected and resolved by the hippocampus, which allows for proper memory retrieval. In the absence of memory interference, hippocampal output is unnecessary to control responding (McNaughton and Wickens 2003), and hippocampal manipulations have no effect. In support of this theory, hippocampal lesions shift approachavoidance conflicts in the direction of approach, but do not affect avoidance when this goal does not conflict with approach (Gray and McNaughton 1983, 2000). By this reasoning, if interference is manifest as ambiguity in the association between CS and testing context, hippocampal inactivation during renewal testing should have no effect in situations where there is no ambiguity in the test context (ABA, $\mathrm{ABB}$ ), but should affect situations in which the testing context has an ambiguous association with the $\mathrm{CS}$ (AAA, AAB, $\mathrm{ABC}$ ). In these situations, performance line responding would result in low levels of freezing. These predictions are supported by our present and previous (Holt and Maren 1999; Corcoran and Maren 2001) results.

It is interesting that in the present study, as well as in pre- vious research (Bouton and Bolles 1979; Bouton and Ricker 1994; Corcoran and Maren 2001; Hobin et al. 2003), the renewal effect is most robust early in the testing phase, and this renewed fear rapidly extinguishes. This pattern of behavior reflects the pattern of hippocampal neuronal activity when rats detect a mismatch between actual experience and an expected outcome based on the memory of previous experience (Fyhn et al. 2002). These data speak to a role for the hippocampus in detecting associative mismatch between stimuli (Honey et al. 1998; Honey and Good 2000). Rapid extinction of the renewed fear response occurs as the mismatch between testing context and CS presentation is resolved over the course of continued CS presentations. Renewal of fear in $\mathrm{AAB}$ and $\mathrm{ABC}$ designs may engage the hippocampus to detect the mismatch that arises when the CS is presented in a context in which it has never been experienced, and hippocampal inactivation blocks the ability to detect this mismatch. In this same vein, behavior in $\mathrm{ABA}$ and $\mathrm{ABB}$ designs would be predicted not to require the hippocampus, insofar as there is no associative mismatch between the training/testing context and CS presentation there.

The results of the present experiments further our understanding of the role of the hippocampus in the contextual retrieval of fear memory after extinction. By viewing renewal designs according to the amount of ambiguity fostered upon retrieval testing between CS-US and CS-no US memories, we have not only resolved disparities among previous reports on the role of the hippocampus in renewal, but have also fit renewal behavior and the effects of hippocampal inactivation on that behavior into a theoretical framework for hippocampal function in general memory retrieval. Understanding the neurobiological bases of extinction and renewal marks a critical step in creating clinical treatments for fear disorders in humans.

\section{MATERIALS AND METHODS}

\section{Subjects}

The subjects were 47 adult male Long-Evans rats (200-224 g) obtained from a commercial supplier (Harlan Sprague Dawley). After arrival, the rats were housed individually in plastic hanging cages on a 14:10 h light/dark cycle (lights on at 7:00 a.m.) and were allowed unlimited access to food and water. After being housed, the rats were handled (10-20 sec per rat per day) for $5 \mathrm{~d}$, to habituate them to the experimenter.

\section{Surgery}

One week before behavioral testing, rats were implanted with stainless-steel guide cannulas aimed at the DH. Rats were treated with atropine methyl nitrate $(\sim 0.03 \mathrm{mg} / \mathrm{kg}$, i.p.), anesthetized with sodium pentobarbital (Nembutal; $65 \mathrm{mg} / \mathrm{kg}$, i.p.), and mounted in a Kopf stereotaxic apparatus (Kopf Instruments). The scalp was incised and retracted, and the head was positioned to place bregma and $\lambda$ in the same horizontal plane. Small holes were drilled through the skull for bilateral placement of stainless steel guide cannulas (23 gauge; $10 \mathrm{~mm}$ in length; Small Parts, Inc.) into the $\mathrm{DH}(3.8 \mathrm{~mm}$ posterior, $2.5 \mathrm{~mm}$ lateral, $2.5 \mathrm{~mm}$ ventral to bregma) and three jeweler's screws. Cannulas were affixed to the skull and the scalp incision was closed with dental acrylic. After surgery, stainless-steel obturators (30 gauge; $10 \mathrm{~mm}$ in length; Small Parts) were placed in the guide cannulas. Obturators were replaced every other day throughout the remainder of the experiment.

\section{Behavioral Apparatus}

Eight identical observation chambers $(30 \times 24 \times 21 \mathrm{~cm}$; MEDAssociates) were used in all experiments. The chambers were constructed from aluminum (side walls) and Plexiglas (rear wall, ceiling, and hinged front door) and were situated in soundattenuating cabinets located in a brightly lit and isolated room. 
The floor of each chamber consisted of 19 stainless steel rods (4 $\mathrm{mm}$ in diameter) spaced $1.5 \mathrm{~cm}$ apart (center-to-center). Rods were wired to a shock source and solid-state grid scrambler (MEDAssociates) for the delivery of footshock USs. A speaker mounted outside of a grating in one wall of the chamber was used for the delivery of acoustic CSs. Sensory stimuli were adjusted within these chambers to generate two distinct contexts. For the first context, a 15-W houselight mounted opposite the speaker was turned on, and room lights remained on. The chambers were cleaned with a $1 \%$ acetic acid solution, and stainless-steel pans containing a thin film of the same solution were placed underneath the grid floors before the rats were placed inside to provide a distinct odor. Ventilation fans in each chest supplied background noise ( $65 \mathrm{~dB}$, A scale). Rats were transported to this context in white plastic boxes. For the second context, all room and chamber houselights were turned off; a pair of $40 \mathrm{~W}$ red lights provided illumination. Additionally, the doors on the soundattenuating cabinets were closed, the ventilation fans were turned off, and the chambers were cleaned with a $1 \%$ ammonium hydroxide solution. To provide a distinct odor, stainlesssteel pans containing a thin film of this solution were placed underneath the grid floors before the rats were placed inside. Rats were transported to this context in black plastic boxes.

\section{Procedure}

Rats were given $1 \mathrm{wk}$ after surgery for recovery, then submitted to three phases of training as folows: fear conditioning, extinction, and retrieval testing. For this experiment, context A refers to the context in which fear conditioning occurred, and context $\mathrm{B}$ refers to the alternate context. The actual contexts in which fear conditioning, extinction, and testing occurred were counterbalanced across groups. For fear conditioning, rats were transported in squads of eight and placed in the conditioning chambers; chamber position was counterbalanced for each squad. The rats received five tone $(10 \mathrm{sec} ; 80 \mathrm{~dB} ; 2 \mathrm{kHz})$-footshock $(1 \mathrm{sec} ; 1 \mathrm{~mA})$ trials (70-sec intertrial interval) beginning 3 min after being placed in the chambers. Sixty seconds after the final shock, the rats were returned to their home cages.

Twenty-four hours after the conditioning session, rats were assigned to two groups that were extinguished to the tone either in the training context (context A) or in a novel context (context B). The extinction phase lasted $5 \mathrm{~d}$. On each extinction day, each rat spent $38 \mathrm{~min}$ in both context $\mathrm{A}$ and context $\mathrm{B}$; the order of the context exposure was counterbalanced. In the extinction context, rats received 30 tone CS presentations (10 sec; $80 \mathrm{~dB} ; 2 \mathrm{kHz}$; $60 \mathrm{sec}$ ISI) $3 \mathrm{~min}$ after placement in the context, whereas in the other context, rats received no tone presentations. Approximately 3-4 h elapsed lapsed between placements in the two contexts each day.

Twenty-four hours after the last extinction day, the rats were transported into a novel room to receive intracranial infusions. Rats were transported in squads of four in opaque white plastic buckets with pine shavings covering the floors of the buckets. The squads were counterbalanced for both extinction context and infusion, yielding a total of eight groups in a $2 \times 2 \times 2$ (renewal type $\times$ extinction context $\times$ infusion) design $(n=$ five to six per group). Within each of the two renewal types (ABA/ABB and $\mathrm{AAA} / \mathrm{AAB}$ ) were four groups, called CON/MUS, CON/SAL, INCON/MUS, and INCON/SAL, which were matched across renewal types for levels of freezing on the last extinction day. The labels CON and INCON refer to whether the CS was tested in the context consistent with its extinction $(\mathrm{CON})$ or in the context inconsistent with its extinction (INCON). Upon arrival in the infusion room, the obturators were removed from the rats' guide cannulas. Stainless-steel injection cannulas (30 gauge; $11 \mathrm{~mm}$ in length; Small Parts, Inc.), which were connected by polyethylene tubing (PE-20; Small Parts, Inc.) to 10- $\mu$ L syringes mounted in an infusion pump (Harvard Apparatus), were placed in the guide cannulas. Rats received an infusion of sterile physiological saline (0.9\%; SAL group) or muscimol ( $1 \mu \mathrm{g} / \mu \mathrm{L}$ dissolved in $0.9 \%$ sterile saline; Sigma; MUS group) at a rate of $0.32 \mu \mathrm{L} / \mathrm{min}$ for $94 \mathrm{sec}$, resulting in a $0.5-\mu \mathrm{L}$ infusion (i.e., $0.5 \mu \mathrm{g}$ of muscimol per hemi- sphere). Under these conditions, muscimol inactivates brain tissue within $2 \mathrm{~mm}$ of the infusion site on the basis of measurements of $\left[{ }^{3} \mathrm{H}\right]$ muscimol binding and 2-deoxyglucose activity (Martin 1991). We assume, then, that our infusion procedure produces a functional inactivation of substantial portion of the DH. After the infusion pumps were shut off, rats remained in the buckets with the injection cannulas in place for $1 \mathrm{~min}$ to allow for diffusion of the drug. The injection cannulas were removed and obturators were placed in the guide cannula. Rats were then returned to their home cages.

A total of 20-25 min later, the rats were brought back to the conditioning chambers for retrieval testing. Testing consisted of one 8-min continuous CS presentation $(80 \mathrm{~dB} ; 2 \mathrm{kHz} ; 60 \mathrm{sec}$ ISI) beginning $2 \mathrm{~min}$ after placement in the context.

Fear to the tone CS during the extinction and testing phases was assessed by measuring freezing behavior (see Maren 1998). Each conditioning chamber rested on a load-cell platform that was used to record chamber displacement in response to each rat's motor activity. To ensure interchamber reliability, we calibrated each load-cell amplifier to a fixed chamber displacement. The output of each chamber's load cell was set to a gain that was optimized for detecting freezing behavior. Load-cell amplifier output $(-10$ to $+10 \mathrm{~V})$ from each chamber was digitized and acquired on-line using Threshold Activity software (MEDAssociates). Absolute values of the load-cell voltages were computed and multiplied by 10 to yield a load-cell activity scale that ranged from 0 to 100 .

For each chamber, load-cell activity was digitized at $5 \mathrm{~Hz}$, yielding one observation per rat every $200 \mathrm{msec}$ (300 observations per rat per minute). In all experiments, freezing was quantified by computing the number of observations for each rat that had a value less than the freezing threshold (load-cell activity $=5$; when animals exhibit freezing, load-cell activity is at or below this value). To avoid counting momentary inactivity as freezing, we scored an observation as freezing only if it fell within a contiguous group of at least five observations that were all less than the freezing threshold. Thus, freezing was only scored if the rat was immobile for at least $1 \mathrm{sec}$. For each session, the freezing observations were transformed to a percentage of total observations. Due to technical difficulty, freezing data from the second day of extinction were not collected.

\section{Histology}

Histological verification of cannula placements was performed after behavioral testing. Rats were perfused across the heart with physiological saline, followed by a $10 \%$ formalin solution. After extraction from the skull, brains were post-fixed in $10 \%$ formalin solution for $2 \mathrm{~d}$, at which time the solution was replaced with a $10 \%$ formalin $/ 30 \%$ sucrose solution until sectioning. Sections $\left(40-\mu \mathrm{m}\right.$ thick) were cut on a cryostat $\left(-19^{\circ} \mathrm{C}\right)$, wet-mounted on microscope slides, and stained with $0.25 \%$ thionin for visualization of cannula and injector tracts.

\section{Data Analysis}

For each session, the freezing data were transformed to a percentage of the total observations, a probability estimate that is amenable to analysis with parametric statistics. These probability estimates of freezing were analyzed using ANOVA. Post hoc comparisons in the form of Fisher's PLSD tests were performed after a significant omnibus F-ratio. All data are represented as means \pm SEMs.

\section{ACKNOWLEDGMENTS}

This work was supported by Grant MH065961 from the National Institute of Mental Health (S.M.) and by a National Science Foundation Graduate Research Fellowship (K.A.C.). We thank Omry Maoz for technical assistance.

\section{REFERENCES}

Bouton, M.E. 1994. Context, ambiguity, and classical conditioning.

Curr. Dir. Psychol. Sci. 3: 1-5. 
. 2002. Context, ambiguity, and unlearning: Sources of relapse after behavioral extinction. Biol. Psychiat. 52: 972-986.

Bouton, M.E. and Bolles, R.C. 1979. Contextual control of the extinction of conditional fear. Learn. Motiv. 10: 445-466.

Bouton, M.E. and Ricker, S.T. 1994. Renewal of extinguished responding in a second context. Anim. Learn. Behav. 22: 317-324.

Bouton, M.E. and Swartzentruber, D. 1986. Analysis of the associative and occasion-setting properties of contexts participating in a Pavlovian discrimination. J. Exp. Psych.: Anim. Behav. Processes 12: $333-350$

Corcoran, K.A. and Maren, S. 2001. Hippocampal inactivation disrupts contextual retrieval of fear memory after extinction. J. Neurosci. 21: 1720-1726.

Davis, M.E. and Myers, K.M. 2002. The role of glutamate and $\gamma$-aminobutyric acid in fear extinction: Clinical implications for exposure therapy. Biol. Psychiat. 52: 998-1007.

Frankland, P.W., Cestari, V., Filipkowski, R.K., McDonald, R.J., and Silva, A.J. 1998. The dorsal hippocampus is essential for context discrimination but not for contextual conditioning. Behav. Neurosci. 112: $863-874$.

Frohardt, R.J., Guarraci, F.A., and Bouton, M.E. 2000. The effects of neurotoxic hippocampal lesions on two effects of context after fear extinction. Behav. Neurosci. 114: 227-240.

Fyhn, M., Molden, S., Hollup, S., Moser, M-B., and Moser, E.I. 2002. Hippocampal neurons responding to first-time dislocation of a target object. Neuron 35: 555-566.

Good, M. and Honey, R.C. 1991. Conditioning and contextual retrieval in hippocampal rats. Behav. Neurosci. 105: 499-509.

Good, M., de Hoz, L., and Morris, R.G. 1998. Contingent versus incidental context processing during conditioning: Dissociation after excitiotoxic hippocampal plus dentate gyrus lesions. Hippocampus 8: $147-159$.

Gray, J.A. and McNaughton, N. 1983. Comparison between the behavioural effect of septal and hippocampal lesions: A review. Neurosci. Biobehav. Rev. 7: 119-188.

. 2000. The Neuropsychology of anxiety: An enquiry into the functions of the septo-hippocampal system. Oxford: Oxford University Press, London.

Hirsh, R. 1974. The hippocampus and contextual retrieval of information from memory: A theory. Behav. Biol. 12: 421-444.

Hobin, J.A., Goosens, K.A., and Maren, S. 2003. Context-dependent neuronal activity in the lateral amygdala represents fear memories after extinction. J. Neurosci. 23: 8410-8416.

Holt, W.G. and Maren, S. 1999. Muscimol inactivation of the dorsal hippocampus impairs contextual retrieval of fear memory. $J$. Neurosci. 19: 9054-9062.

Honey, R.C. and Good, M. 1993. Selective hippocampal lesions abolish the contextual specificity of latent inhibition and conditioning. Behav. Neurosci. 107: 23-33.

. 2000. Associative components of recognition memory. Curr. Opin. Neurobiol. 10: 200-204.
Honey, R.C., Watt, A., and Good, M. 1998. Hippocampal lesions disrupt an associative mismatch process. J. Neurosci. 18: 2226-2230.

Kim, J.J. and Fanselow, M.S. 1992. Modality-specific retrograde amnesia of fear. Science 256: 675-677.

Lovibond, P.F., Preston, G.C., and Mackintosh, N.J. 1984. Context specificity of conditioning, extinction, and latent inhibition. J. Exp. Psych.: Anim. Behav. Processes 10: 360-375.

Maren, S. 1998. Overtraining does not mitigate contextual fear conditioning deficits produced by neurotoxic lesions of the basolateral amygdala. J. Neurosci. 18: 3088-3097.

Maren, S. and Holt, W. 2000. The hippocampus and contextual memory retrieval in Pavlovian conditioning. Behav. Brain Res. 110: 97-108.

Maren, S., Aharonov, G., and Fanselow, M.S. 1997. Neurotoxic lesions of the dorsal hippocampus and Pavlovian fear conditioning in rats. Behav. Brain Res. 88: 261-274.

Martin, J.H. 1991. Autoradiographic estimation of the extent of reversible inactivation produced by microinjection of lidocaine and muscimol in the rat. Neurosci. Lett. 127: 160-164.

McNaughton, N. and Wickens, J. 2003. Hebb, pandemonium and catastrophic hypermnesia: The hippocampus as a suppressor of inappropriate associations. Cortex 39: 1139-1163.

Pavlov, I.P. 1927. Conditioned reflexes. Oxford University Press, London.

Rudy, J.W. and O'Reilly, R.C. 2001. Conjunctive representations, the hippocampus, and contextual fear conditioning. Cogn. Affect. Behav. Neurosci. 1: 66-82.

Shapiro, M.L. and Olton, D.S. 1994. Hippocampal function and interference. In Memory systems (eds. D. Schacter and E. Tulving), Vol. 1., pp. 87-117. MIT Press, Cambridge, MA.

Spear, N.E. 1973. Retrieval of memory in animals. Psychol. Rev. 80: $163-194$.

Swanson, L.W. 1992. Brain maps: Structure of the rat brain. Elsevier, New York.

Tulving, E. and Thomson, D.M. 1973. Encoding specificity and retrieval processes in episodic memory. Psychol. Rev. 80: 352-373.

Wan, R-Q., Pang, K., and Olton, D.S. 1994. Hippocampal and amygdaloid involvement in nonspatial and spatial working memory in rats: Effects of delay and interference. Behav. Neurosci. 108: $866-882$.

Wilson, A., Brooks, D.C., and Bouton, M.E. 1995. The role of the rat hippocampal system in several effects of context in extinction. Behav. Neurosci. 109: 828-836.

Winocur, G. 1979. Effects of interference on discrimination learning and recall by rats with hippocampal lesions. Physiol. Behav. 1979 22: 339-345.

. 1985. The hippocampus and thalamus: Their roles in short- and long-term memory and the effects of interference. Behav. Brain Res. 1985 16: 135-152.

Received April 2, 2004; accepted in revised form July 28, 2004. 


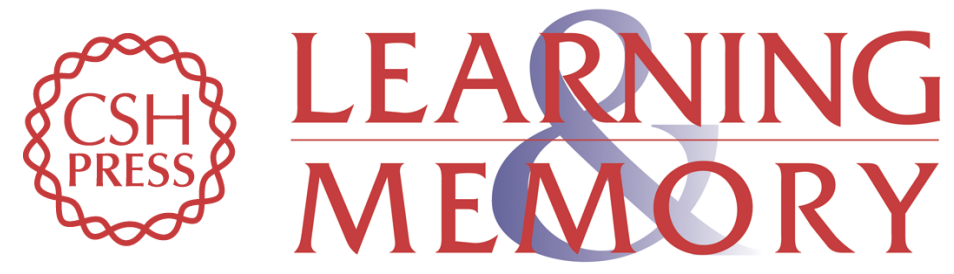

\section{Factors Regulating the Effects of Hippocampal Inactivation on Renewal of Conditional Fear After Extinction}

Kevin A. Corcoran and Stephen Maren

Learn. Mem. 2004, 11:

Access the most recent version at doi:10.1101//m.78704

References This article cites 31 articles, 6 of which can be accessed free at: http://learnmem.cshlp.org/content/11/5/598.full.html\#ref-list-1

License

Email Alerting

Receive free email alerts when new articles cite this article - sign up in the box at the Service top right corner of the article or click here. 